\title{
Understanding Satellite Image-Based Green Space Distribution for Setting up Solutions on Effective Urban Environment Management ${ }^{\dagger}$
}

\author{
Tham Thi Ngoc Han ${ }^{1}$, Pham Khanh Hoa ${ }^{1}$, Ha Bao Khoa ${ }^{2}$ and Tran Thi Van 1,* \\ 1 Faculty of Environment and Natural Resources, Ho Chi Minh City University of Technology, Vietnam \\ National University Ho Chi Minh City, 268 Ly Thuong Kiet Street, District 10, Ho Chi Minh City, Vietnam; \\ thamhan.3001@gmail.com (T.T.N.H.); 91301390@hcmut.edu.vn (P.K.H.) \\ 2 Shannon School of Business, Cape Breton University, 1250 Grand Lake Rd, Sydney, NS B1P 6L2, Canada; \\ habaokhoa262@gmail.com \\ * Correspondence: tranthivankt@hcmut.edu.vn; Tel.: +84-028-091-918-8485 \\ + Presented at the 1st International Electronic Conference on Geosciences, 15-30 June 2018; Available online: \\ https://iecg_2018.sciforum.net/.
}

Published: 14 June 2018

\begin{abstract}
Urban environments are vulnerable, as there is a change in the surface structure of the land cover. Particularly when natural vegetation cover is converted to construction land, which is covered by impervious surfaces, the accumulation of solar energy is increased. This has led to an increasingly urban environment that is becoming more severe and threatening to affect the quality of life in urban populations. Satellite images are very helpful in determining the distribution of green space. This paper presents the results of analyzing urban land cover for determining green space (GS) distribution for Ho Chi Minh City (HCMC). In 2017, the vegetation land of the old 13 urban districts accounts for only one third of the impervious surface. In contrast, in the area of six new urban districts there is a high percentage of urban green space, accounting for nearly twice the proportion of the impervious surface type. This shows that the old inner city area is seriously lacking GS area. Most districts have a very low GS index, less than $10 \mathrm{~m}^{2} /$ person, while in some districts it is even less than $3 \mathrm{~m}^{2} /$ person. In the eastern part of the city, District 9 has the highest GS index, ensuring a good life quality. Recent research has provided a number of management solutions to improve and develop the GS area, thus enhancing the environment quality and the life quality for the population. Moreover, our research results contribute to the effective urban management of HCMC.
\end{abstract}

Keywords: impervious surface; green space; satellite image; supervised classification; urban environment

\section{Introduction}

In urban planning, green space (GS) is an essential function and is considered as the lung of the city. It plays an important role in human life. However, the rapid increase in the area of impervious surface in urban areas, in addition to significantly reducing the city's GS, has a strong negative impact on the quality of the living environment. The expansion and increase in the density of impermeable surfaces has the consequence of increasing the city's air temperature due to the thermal radiation of the concrete; increasing waste and exacerbating the problem of landfill and waste disposal in high urban areas; and increasing flooding. Furthermore, it leads to a decrease in the quality and volume of groundwater due to the loss of surface water absorption [1]. 
Ho Chi Minh City (HCMC) is Vietnam's largest city in terms of size and economic potential. It operates as a nucleus; a driving force for socioeconomic development in the south and south-central region. However, at present, the policy of GS in HCMC has not been paid enough attention. Urban growth and a lack of necessary government resources are the current weaknesses in the management and development of the quantity and quality of GS and street trees. In fact, in existing residential areas in urban districts, green systems and parks are in serious shortage. The rapid pace of urbanization in previously unplanned urban areas has spontaneously developed areas with dense populations, but lacking green spaces and public space. This leads to a low quality of life and serious environmental pollution, resulting in many consequences for socioeconomic development and affecting people's life, health, and morale.

This article presents a study on the status of urban distribution, using satellite data and remote sensing image processing methodology for the assessment of urban environmental quality in the inner city. With our results, we aim to contribute to green urban development planning in the future.

\section{Methodology}

\subsection{Data and Image Pre-Processing}

The data used in this study are Sentinel-2A optical imagery-multi-spectral images with 13 spectral bands (443-2190 nm wavelengths) with spatial resolutions of $10 \mathrm{~m}$ (four visible and nearvisible bands), $20 \mathrm{~m}$ (six bands in short infrared wavelengths), and $60 \mathrm{~m}$ (three bands in the atmospheric study). Images were acquired on 9 March 2017 in the dry season with minimal cloudiness, in order to minimize the effects of atmospheric conditions.

Sentinel-2A is a type of satellite that provides "optical images" that are susceptible to weather conditions, especially in the rainy season, which is characterized by cloudy conditions. Therefore, the image should be selected in the dry season, without clouds, so that the satellite sensor can clearly see the surface. The research area is the center of HCMC, where urban areas are concentrated, with no agricultural land. In this area, where the population is crowded, the density of built-up land is high. Where the population is less, most of the land is green, provided with water from the natural small rivers in the area. Existing bare lands are categorized as construction works for new urban areas. Therefore, selecting the image in the dry season to assess GS for urban areas in this study may be sufficient for the correct identification of land use types.

This study only extracted surface soil to evaluate urban green spaces. So, with the good cloudless imagery, the atmospheric correction phase can be ignored. The images were manipulated geometrically according to the national coordinates of VN2000, WGS84. Image correction was less than 0.5 pixels.

\subsection{Method}

\subsubsection{Supervised Classification}

In order to evaluate the status of green distribution, the study conducted a classification algorithm with a supervised classification method in order to classify land surface entities. This is a classification method where taxonomies are established based on sampling regions, and decision rules based on the appropriate algorithms for labeling pixels for specific coverage areas are employed. In this research, the supervised classification method with MLC (Maximum Likelihood Classifier) was used. This method considers each class in each spectrum channel to have a standard distribution. Pixels are classified into the class that has the highest probability. The classification system employed in this case includes four main targets: water, bare land, vegetation, and impervious surface. Urban and bare land are then classified into other land categories for comparison with vegetation land in the GS assessment.

The accuracy of classification is evaluated based on the error matrix and norms such as the overall accuracy and Kappa coefficient [2]. The overall accuracy is computed by the number of correctly classified pixels divided by the number of pixels used for classification. The high accuracy 
of commonly accepted classifications is over $85 \%$. The Kappa coefficient $(\mathrm{K})$ is used as a measure of the accuracy of image classification. It shows the basic difference between what is real about the error of the deviation of the matrix and the total number of changes indicated by the row and column. The Kappa coefficient is usually between 0 and $1 . \mathrm{K}>0.8$ commonly indicates a high accuracy of the accepted classification.

\subsubsection{Urban Green Space Index Assessment Method (per Capita)}

Based on many research studies that developed the urban environment quality index in Vietnam, the index of "green area/capita" is an important index to evaluate environment quality and urban space [3]. This index is built to assess the quality of urban green coverage. The urban green space index (GSI) after calculation is compared with The Vietnam National standard TCVN 9257:2012 [4] to evaluate the status of urban GS distribution.

\section{Results and Discussion}

\subsection{Accuracy Assessment of Land Cover Classification}

Verification points were made after classification across the study area. Each district included 10 samples of four types of targets in the classification system, based on the fieldwork and observed in the very-high-resolution images of Google Earth. This field set was used to build the test set. For each target layer, the sample set ranged from 600-900 points. This sample was then compared with the classification image. The results of the classification error showed that the overall accuracy was $96.63 \%$ and the Kappa coefficient was 0.96 . With this accuracy, the result is reliable enough.

\subsection{Distribution Status of GS}

In terms of administrative units, the 19 districts of HCMC consist of 13 old urban districts and six new urban districts. The statistical results of the area and the percentage of each land cover from the classification algorithm for 19 districts of HCMC are presented in Table 1 and Figure 1. Overall, by 2017 , the vegetation land cover type accounted for the largest proportion, amounting to about $40.26 \%$ of the area across 19 districts. Next, the impervious surface covered $38.68 \%$ of the total area. However, when comparing statistics between the 13 old urban districts and the six new urban districts, there is a big difference between the ratio of land cover. In particular, in the old inner city, the vegetation land cover type only accounts for $22.62 \%$, while in the six new districts the area ratio is double, reaching $47.39 \%$. Meanwhile, the impervious surface land cover type, only accounted for $28.79 \%$ in the six new districts, while in the old inner city this value is twice as high at $63.19 \%$. There is clearly a difference in urban development in these two areas. In general, the amount of vegetation land cover in the 13 districts in the inner city is only equal to one third of the impervious surface. In contrast, the six new urban districts have a high percentage of urban GS area, which is almost twice the amount impervious surface land cover type.

Table 1. Statistics of land cover by area percentage (\%) of 19 districts in Ho Chi Minh City (HCMC).

\begin{tabular}{lcccc}
\hline \multirow{2}{*}{ Zone } & \multicolumn{4}{c}{ Area Percentage (\%) of Total Area } \\
\cline { 2 - 5 } & Vegetation & Water & Impervious Surface & Bare Land \\
\hline Thirteen old urban districts & 22.62 & 4.05 & 63.19 & 10.03 \\
Six new urban districts & 47.39 & 7.74 & 28.79 & 16.04 \\
Three districts in the eastern part & 51.38 & 8.98 & 23.70 & 15.99 \\
Whole study area & 40.26 & 6.67 & 38.68 & 14.31 \\
\hline
\end{tabular}




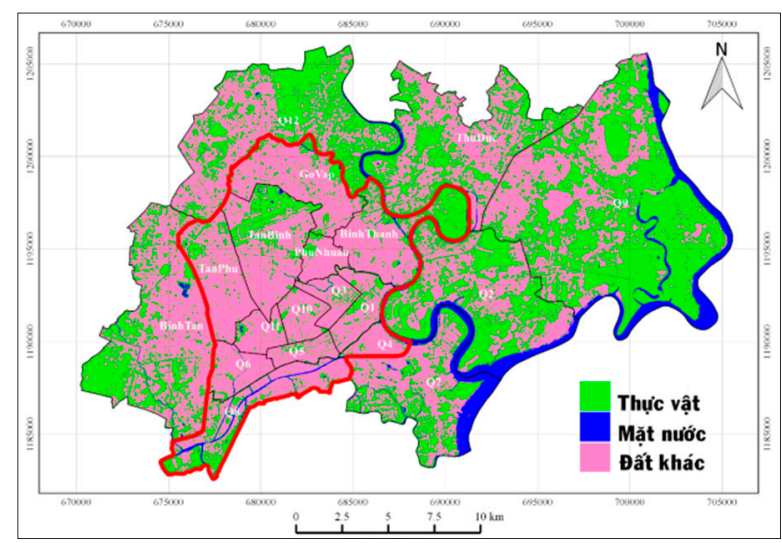

Figure 1. Land cover of 19 districts in HCMC in 2017. (The red polyline is the boundary of the 13 old urban districts).

Focusing on the distribution of GSs, in the central metropolitan area of the city, the trees are sparse, scattered, and mainly concentrated in parks. The rest is mostly built-up land. Meanwhile, the six new districts are dominated by the development of green areas, and built-up land is not as widespread. Specifically, in the 13 old urban districts, up to eight out of the 13 districts are characterized by an area of impervious surface occupying more than $70 \%$. In contrast, only three of the 13 districts include an area of vegetation land amounting to about $30 \%$. The remaining districts have $10-20 \%$ of natural vegetation area. In the six new districts, most of the districts have a GS area of over $40 \%$. In particular, three districts in the eastern part of the city have the largest areas of vegetation, accounting for $51.38 \%$ of the whole area. Of these three, District 9 has the highest rate of $57.87 \%$ in the whole study area (Figure 2 ).

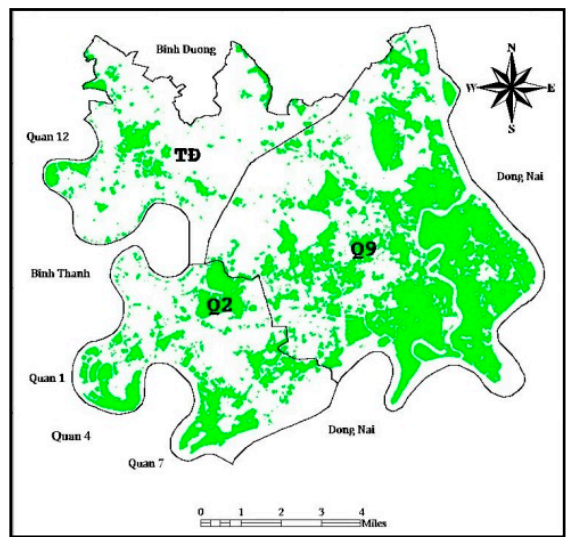

Figure 2. Green space (GS) distribution of the eastern part of HCMC in 2017.

\subsection{Urban GSI and the Consequences of Reducing Greenery}

\subsubsection{The Status of Urban GSI in 2017}

GSI has been used as an indicator of environmental quality and urban spatial planning in countries around the world. The Vietnam National standard TCVN 9257: 2012 provided the standard rate for public green areas for special cities such as HCMC, ranging from 12 to $15 \mathrm{~m}^{2} /$ person [4]. According to the Statistics Department, the population of the study area by the end of 2016 was $6,616,684$, while the total natural area was $198,910,500 \mathrm{~m}^{2}$. The calculated results show that the average GSI throughout the study area in early 2017 reached about $30 \mathrm{~m}^{2} /$ person. Therefore, considering the average for all 19 districts of HCMC, the urban GSI standard is exceeded. However, this figure is mainly due to the contribution of green area from the six new districts, with an index of $67.43 \mathrm{~m}^{2} /$ person, while in the old inner city the GSI is only $7.76 \mathrm{~m}^{2} /$ person. 
The diagram in Figure 3 shows that the six new urban districts have a total natural area of $166,763,100 \mathrm{~m}^{2}$, which is five times larger than the old inner city. However, the population of these new districts is small $(2,473,179$ people). Therefore, the GSI here presents a very high value with an average of $67.43 \mathrm{~m}^{2} /$ person. The highest GSI falls in District 9, being $227.01 \mathrm{~m}^{2} /$ person. The lowest GSI belongs to Binh Tan district, being $28.46 \mathrm{~m}^{2} /$ person. Thus, all six new districts of HCMC have a GSI value in excess of the standard in TCVN 9257: 2012. Particularly in the east of the city, there are two districts (Districts 9 and 2) that exceed the standard by 10 times.

Meanwhile, the 13 old urban districts represent an area of 3214.74 ha, but their population is nearly double that of the six new districts $(4,143,505$ people), accounting for a very low GSI. The average GSI of the whole area reaches only $7.76 \mathrm{~m}^{2} /$ person. Compared with the standard in TCVN 9257: 2012, only three of the 13 districts have an index of more than $12 \mathrm{~m}^{2} /$ person, which meets the specified threshold. In Tan Binh district, the GSI has exceeded the threshold because of the green area contributed by the golf course at Tan Son Nhat airport. Meanwhile, in residential area there is also a serious lack of green space [5]. Notably, there are districts with a GSI less than $3 \mathrm{~m}^{2} /$ per person. The remaining districts range from 3-9 $\mathrm{m}^{2} /$ person. Thus, the 13 old urban districts of HCMC are lacking green areas, and the existing GS is not enough to ensure the fresh environment necessary for healthy life. Elsewhere in the world, urban standards of GS reaching 20-25 $\mathrm{m}^{2} /$ person are encouraged for a healthy and safe life.

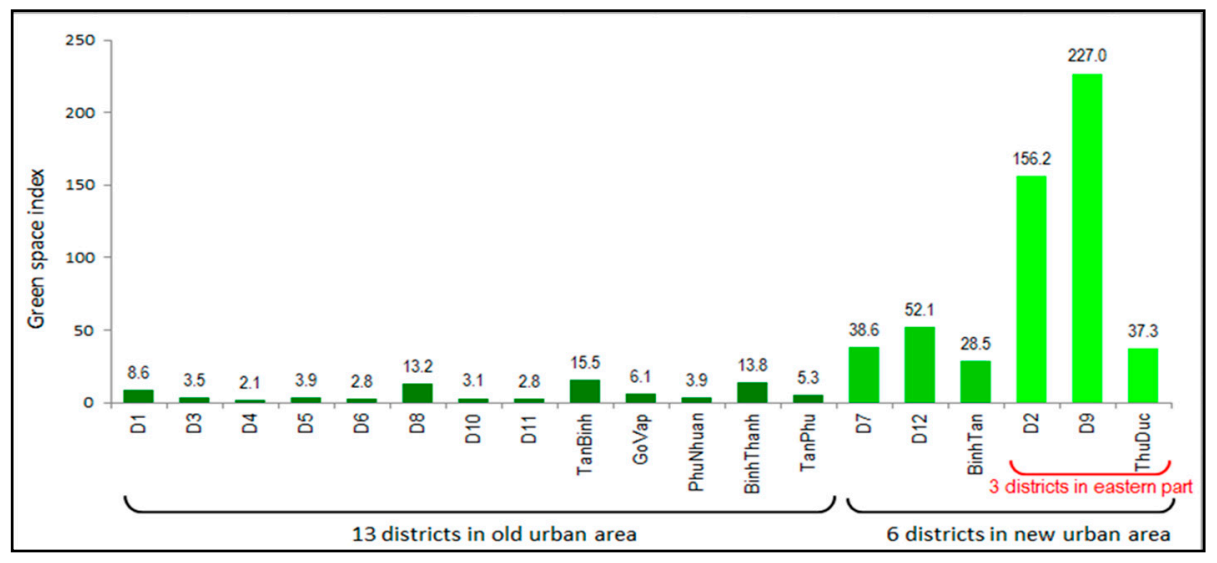

Figure 3. Status of the green space index (GSI) in each district in 2017.

According to the Ministry of Natural Resources and Environment, urban trees play a very important role in bringing benefits to people, society, and the environment in urban areas. Urban trees absorb the sun's heat radiation, reducing the "heat islands" by absorbing $\mathrm{CO}_{2}$ and harmful gases in the environment, and creating the GS to maintain the green landscape for the city. Trees and water in urban areas can reduce the air temperature from $3.3^{\circ} \mathrm{C}$ to $3.9^{\circ} \mathrm{C}$ when the green area reaches $20 \%$ to $50 \%$ of the urban land area [6]. The combined effect of shade and evaporation can reduce the energy required for air conditioning systems by $17 \%$ to $57 \%$, when increasing the vegetation cover by $25 \%$. Urban trees can absorb from $40 \%$ to $50 \%$ of the solar radiation intensity. In particular, trees on both sides of the street can reduce the amount of dust in the air of upper floors of tall buildings from 30 to $60 \%$. An average of 1 hectare of forest or dense garden can absorb $1000 \mathrm{~kg}$ of $\mathrm{CO}_{2}$ and produce 730 $\mathrm{kg}$ of $\mathrm{O}_{2}$ per day. Thus, each urban citizen needs an area of about $10 \mathrm{~m}^{2}$ of green trees or $25 \mathrm{~m}^{2}$ of grass to ensure fresh air for life.

\subsubsection{The Consequences of Reducing Greenery in HCMC}

With the city's expansion rate of $4 \%$ annually, urbanization in HCMC is growing at a much faster rate than other urban areas in Vietnam. In many urbanized areas, green belts are not planned and protected. As a consequence, the hot, stuffy air will allow the "island heat" phenomenon to occur, resulting in increasing rainfall and higher numbers of storms in the city. The rainy season of recent years in the city and the record of 20 hurricanes in the country in 2017 is the best evidence for the 
consequences of this phenomenon [6]. These rains are the result of the decline of urban green space, and have a indirect impact on urban floods.

In addition, the air pollution situation in the city is becoming increasingly complex. Specifically, the results of measurements at six air monitoring stations located at the typical locations of air pollution in the city showed that $89 \%$ of air samples do not meet standards. They continuously indicate a high risk for human health. The amount of Particulate Matter, also known as particle pollution, that is generated by smoke and dust is the cause leading pollution in the city. In addition, the air pollution caused by $\mathrm{Pb}$ has also increased rapidly. Concentrations of $\mathrm{NO}_{2}$ measured at the monitoring stations exceeded the permitted standard and showed an increasing trend [7].

The lack of GS also affects the health of people, causing asphyxia due to respiratory failure, blood poisoning, and even death. Respiratory disease represented the highest rate of "sick people" (17.3\%) in morbidity in 2015 in Vietnam, including respiratory disease, pregnancy and postpartum, circulatory, gastrointestinal, septic and parasitic diseases, and represented the second highest mortality rate $(16.9 \%)$ after circulatory disease [8].

\subsection{Solutions}

The land cover status reported in this study shows that there is an uneven distribution of land use types among districts; in some places GS is lacking, while in other places it is redundant. In order to solve and overcome this situation, the authorities should take measures to consolidate, expand, and develop the system of urban GS, so as to better serve the health and spiritual life of residents.

In the 13 old inner city districts, houses and other buildings are dense and there is a lack of vacant land, so growing trees in a concentrated manner will be difficult. However, it is possible to increase the planting of tall trees with canopies between residential areas, along the roadside, or along road dividers. The upper part of the buildings should design green roofs and green walls. In residential areas, it is recommended to plant more trees on balconies and walls.

The new six districts are still in the urbanization phase, so new plans need to balance built-up land and greenery, creating a green belt for the area of the 13 old urban districts. Specifically, it is necessary to avoid the construction of concentrated houses such those found in the 13 old urban districts. Land funds should be reserved for parks and lakes. Particularly in the east of the city, District 9 is characterized by lowlands, with many rivers and canals. Conservation areas should be developed with many green trees and lakes to create an ecological environment for urban inhabitants.

\section{Conclusions}

Rapid urbanization in HCMC, leading to a reduction in green space and an increase in urban land, has led to consequences impacting on the quality of life and environment. This research study used satellite data and remote sensing techniques to evaluate land cover in urban areas. The statistical results of the land cover distribution and the GSI calculations showed that HCMC's GS distribution is uneven. Urban green space is concentrated in six new districts, which are not very urbanized. At the same time, the area of 13 old districts in the inner city achieved a very low GSI. The failure to meet green standards affects the development of urban HCMC, causing damage to people and property. Therefore, from the results and the observed consequences, the study suggested some solutions to overcome the current green shortage as well as to control the development of green urban areas in HCMC.

\section{References}

1. Tu, D.T.; Hai, T.Q.; Ha, N.T.T.; Ngan, N.T.M. Using multi-time LANDSAT images to research progress of urbanization in Da Nang city for protecting urban environment. Environ. Mag. 2015, 8, 67-71

2. Thanh, H.X. Establishment of land cover maps based on remote sensing analysis and processing. J. Irrig. Eng. Environ. Sci. 2010, 29, 27-33

3. Tran Quang Loc, P.K.L. Researching and building urban environment quality index and applying to some urban areas in Vietnam. Sci. Mag. 2012, 74B, 93-102. 
4. National Standard TCVN 9257: 2012. Planning for Green Trees for Public Use in Urban Centers-Design Standards; National Standard: Pensacola, FL, USA, 2012.

5. Prime Minister. Decision Approving the Adjustment of the Master Plan on Construction of Ho Chi Minh City up to 2025; No. 24 / QD-TTg; Prime Minister: Hanoi, Vietnam, 2010.

6. Ministry of Natural Resources and Environment. National Environment Status Report 2016; Ministry of Natural Resources and Environment: Hanoi, Vietnam, 2017.

7. Department of Environmental Protection HCMC. Ho Chi Minh City: 89\% samples of air quality exceeded standards. Available online: http://hepa.gov.vn/content/tintuc_chitiet.php?catid=252\&subcatid=0\&newsid= 235\&langid=0 (accessed on 1 July 2017).

8. Nhan Dan Newspaper. Serious Air Pollution Threatens Human Health. Available online: http://www.nhandan.com.vn/khoahoc/item/31862202-o-nhiem-khong-khi-nghiem-trong-de-doa-suckhoe-con-nguoi.html (accessed on 1 July 2017).

(C) 2018 by the authors. Licensee MDPI, Basel, Switzerland. This article is an open access article distributed under the terms and conditions of the Creative Commons Attribution (CC BY) license (http://creativecommons.org/licenses/by/4.0/). 